What is materialism? Testing two dominant perspectives on materialism in the marketing literature

\author{
Srikant MANCHIRAJU \\ Florida State University, Florida, United States of America \\ Zlatan KRIZAN \\ Iowa State University, Iowa, United States of America
}

\begin{abstract}
Materialism is defined as the importance an individual attaches to worldly possessions, which has been considered as an important construct in consumer behavior and marketing literature. There are two dominant perspectives on individual materialism in the marketing literature that focus on (1) personality traits or (2) individual personal values. However, several scholars have questioned the aforementioned materialism conceptualizations. Therefore, the present study directly compares the constructs of personality materialism and value materialism. Structural equation modeling was employed to address the following issues: (1) what are the key conceptual dimensions of materialism, (2) how much do they overlap, and (3) what is their discriminant validity in predicting outcomes linked to materialism. We suggest these two dominant perspectives on individual materialism are two distinct constructs, as they shared only 21 percent of common variance. Furthermore, we stress the multi-faceted nature of materialism, with an emphasis on future research directions related to materialism in marketing.
\end{abstract}

Keywords: materialism, individual perspective, personality trait, personal value, marketing, conceptualizations.

Please cite the article as follows: Manchiraju, S. and Krizan, Z. (2015), "What's materialism? Testing two dominant perspectives on materialism in the marketing literature", Management \& Marketing. Challenges for the Knowledge Society, Vol. 10, No. 2, pp. 90-103, DOI: 10.1515/mmcks-2015-0008.

"You know that we are living in a material world. And I am a material girl".

\title{
Introduction
}

Madonna (Sire Records, 1984)

We live in the world of unprecedented material abundance (Van Boven and Gilovich, 2003). As the opening quote illustrates, materialism has become a way of "the good life" in western societies, where individuals strive for materialistic goods and lifestyle (Scitovisky, 1976; Van Boven and Gilovich, 2003). Materialism is defined as "the importance a consumer attaches to worldly possessions" (Belk, 1984, p. 291). Noting the importance of materialism, Twitchell (1999) maintained, “[o]f the $20^{\text {th }}$ century's various -isms, it has been the one that has ultimately triumphed" (p. 16). Materialism is a complex, multi-faceted phenomenon, extensively studied by scholars from various fields, including advertising, anthropology, consumer behavior and marketing, economics, psychology, political science, and social sciences (Larsen et al., 1999;

Correspondence: Srikant Manchiraju srikantmanchiraju @gmail.com 
Manchiraju, 2013; Mannion and Brannick, 1995). Furthermore, substantial consumer behavior and marketing literature (e.g., Belk, 1984; Manchiraju, 2013; Richins and Dawson, 1992) have been dedicated to the concept of materialism, which has been maintained to have implications for advertisers, marketing managers, and public policy makers.

However, the term "materialism" is used very loosely (Richins and Dawson, 1992). Accordingly, materialism has been viewed from socio-cultural as well as individual differences perspectives (Hunt et al., 1996). The former perspective examines cultures in which the majority of the people in the society highly value material objects (Larsen et al., 1999). On the other hand, the latter perspective compares people who differ in their valuations of material objects (Larsen et al., 1999). In other words, individuals who value materialism are especially likely to pursue material possessions and the accumulation of income and wealth (Richins and Dawson, 1992).

Although understanding materialism at a cultural level is important, examining individual differences in materialism can provide important insights into the psychology of materialism (Richins and Dawson, 1992). Critically, various scholars have conceptualized individual differences in materialism in distinct ways (Shrum et al., 2012). Materialism has been conceptualized as an attitude, belief, lifestyle, state (i.e., mood), trait, and value (e.g., Ahuvia, 2008; Belk, 1985; Chang and Arkin, 2002; Richins and Dawson, 1992). In empirical marketing research, several instruments have been developed to measure materialism at the individual level, based on the aforementioned conceptualizations. Of particular interest for the present study are the two dominant perspectives, namely those that refer to materialism as a personality trait or a personal value (for socio-cultural perspective see Ghadrian 2010; Manchiraju, 2013).

Materialism has drawn scholarly attention because it seems to carry negative consequences for individuals. For example, materialism is positively related to various psychological illnesses (e.g., paranoia and depression; Kasser and Ryan, 1993), conflicts between spouses (Paduska, 1992), tendency to engage in shoplifting (Larsen et al., 1999), more laissez-faire attitude towards borrowing (e.g., excessive use of credit cards), and a lower rate of saving money (Watson, 2003). Moreover, Kasser (2002) reported that materialistic adolescents were more likely to engage in negative behaviors, such as alcohol and marijuana abuse. Along this vein, some studies focusing on materialism have found a negative relationship between materialism and happiness (e.g., Wright and Larsen, 1993). For example, Wright and Larsen (1993) conducted a meta-analysis of studies to explore the relationships between materialism and life satisfaction. They found individuals who displayed a materialistic orientation reported a lower level of life satisfaction. Similar findings have been reported by other scholars (for a review see Wright and Larsen, 1993).

Clearly, materialism is an important and consequential individual measurement construct (Richins and Dawson, 1992). However, scholars have noted that existing conceptualizations, and by extension materialism measurement scales, have important drawbacks such as negative mutual associations and poor scale reliability (Larsen et al., 1999; Shrum et al., 2012). Given the importance of the topic, in the present study we empirically evaluate the two dominant perspectives on 
MMCKS [individual] materialism by systematically assessing individual differences in both personality-based (hereafter personality materialism) and value-based materialism (hereafter value materialism) (Ahuvia and Wong, 2002).

\section{Personality materialism}

Belk (1985) viewed materialism as a function of individual personality traits. Belk's (1985) materialism scale is one of the most widely used instruments to measure materialism (Ahuvia and Wong, 2002). According to Belk, there are three dominant traits that govern materialism-envy, nongenerosity, and possessiveness. Envy refers to an individual's strong desire for others' possessions. Ahuvia and Wong (1995) noted, "[t]he envious person resents those who own what he wants" (p. 172). Therefore, advertisers frequently appeal to envy to arouse desire for their products (Holbrook, 1987; Murphy, 1998). Nongenerosity is defined as an aversion to giving or sharing one's possessions. In this vein, nongenerosity gives rise to a reluctance to donate one's possessions and a negative attitude towards charity (Ahuvia and Wong, 1995). Possessiveness is defined as the great concern that an individual displays towards one's possessions. Belk (1985) combined these subscales, measuring each of these three traits to obtain an overall measure of materialism. However, Ger and Belk (1996) added a fourth trait-preservation. Preservation refers to a tendency to make one's experiences tangible (e.g., souvenirs). Dawson and Bamossy (1990) employed Belk's (1985) three-dimensional personality materialism scale in the context of American and Dutch consumers. They found that Americans and Dutch people did not significantly differ in their overall materialism level, with levels of the three traits across the samples being similar. However, Ahuvia and Wong (2002) found the preservation subscale yielded negative factor loading; hence, they excluded it from further analysis. Furthermore, alpha coefficients for nongenerosity, envy, and possessiveness were reported as .71, .57, and .44, respectively. The overall scale's alpha coefficient was .71, so only the full scale was utilized for further analyses, since the subscales coefficient alphas were not satisfactory (Ahuvia and Wong, 2002).

\section{Value materialism}

On the other hand, Richins (1994) construed materialism as a value. A value, as defined by Rokeach (1973, p. 161), is "a centrally held, enduring belief which guides actions and judgments across specific situations and beyond immediate goals to more ultimate end-states of existence." Accordingly, Richins and Dawson (1992, p. 308) defined materialism as a "set of centrally held beliefs about the importance of possessions in one's life." According to Richins and Dawson (1992), the three dominant values in the context of materialism are acquisition centrality, happiness, and success. Acquisition centrality is the importance people attach to possessions and the acquisition of material goods as central to their lives. Happiness refers to the belief that owning the desirable possessions promotes wellbeing. Success refers to a belief that an individual's success is dependent upon possession of material goods. Numerous studies have employed Richins and Dawson's (1992) three-dimensional value materialism scale (e.g., Ahuvia and Wong, 2002; Davies et al., n.d.; Eastman et al., 1997; Webster and Beatty, 1997). For example, Webster and Beatty tested the threedimensional structure of value materialism in the U.S. and Thailand. Factor analysis in 
their study revealed the factors loaded per Richins and Dawson's (1992) subscales. In fact, they found a similar level of importance was placed on acquisition centrality and happiness in both the nations, although Thais placed greater importance on success. Likewise, Davies et al. (n.d.) demonstrated the factor reliability of the Richins and Dawson's (1992) three-dimensional value materialism as valid for the sample from both the U.S. and the UK.

\section{Distinguishing between personality and value materialism}

As noted earlier, materialism is an important individual difference construct, but one which has often been blurred in the literature. For example, studies that examine the materialism construct seldom explicitly consider whether they are assessing personality or value materialism. The lack of this distinction has resulted in contradictory results in materialism research (for review, see Larsen et al., 1999). For example, from a critical perspective (i.e., materialism is an inherently bad trait, idem), higher levels of materialism lead to environmental degradation. Conversely, from a bourgeois perspective (i.e., middle class perspective on materialism, which considers materialism as a trait which is inherently good in nature, Gay, 1984; Larsen et al., 1999), a higher level of materialism leads to a higher level of environment protection. Therefore, a better understanding of empirical similarities and dissimilarities of the two materialism conceptualizations is necessary to clarify the materialism construct.

Although prior researchers have assessed the two conceptualizations of materialism together (e.g., Ahuvia and Wong, 2002; Kasser and Ahuvia, 2002), they have not directly tested the competing measurement models for these two views. Therefore, the present study addressed three central questions regarding individual differences in materialistic orientation: (1) what are the key conceptual dimensions of materialism, (2) how much do they overlap, and (3) what is their discriminant validity in predicting outcomes linked to materialism.

\section{Structure of personality and value materialism combined}

To assess the construct(s) underlying the distinct measures of materialism, alternative measurement models for responses to personality materialism and value materialism scales were compared. We used a higher-order measurement modeling to estimate the relationship between personality and value materialism and to determine their degree of their conceptual overlap. Specifically, we tested a higherorder model in which a single, second-order factor [global materialism] underlies responses to the 39 items (21 items related to personality materialism and 18 items related to value materialism).

To test the discriminant validity of the two materialism conceptualizations, we administered the satisfaction with life scale (Diener et al., 1985) and the happiness scale (Lyubomirsky and Lepper, 1999). Given that materialism is often associated with lower life satisfaction and happiness (e.g., Kasser, 2002; Ghadrian, 2010), contrasting relationships of specific materialism factors to these measures will help us evaluate whether they are similarly related to psychological adjustment. 


\section{MMCKS Research method}

\section{Subjects}

94 An online survey was utilized to collect data via Amazon Mechanical Turk (see Buhrmester et al., 2011). The sample for the present study was recruited through Amazon Mechanical Turk (AMT), an online data collection platform managed by Amazon, Inc. (for description see Paolacci et al., 2010). Several studies (Buhrmesteret al., 2011; Paolacci et al., 2010; Sprouse, 2011) have found that the data obtained through AMT were comparable to data collected from laboratory or Internet discussion boards. Consequently, Paolacci et al. (2010) noted that AMT should be considered "as a viable alternative for data collection" (p. 417). Thus, respondents in the sample came from across the United States (ages 18 to 65 years; mean was 29), and they were paid a nominal financial incentive for their participation. Of the 349 valid responses, 59\% were from men.

\section{Materials and procedure}

The survey consisted of items related to personality materialism (Ger and Belk, 1996, 21 items), value materialism (Richins and Dawson, 1992, 18 items), the satisfaction with life scale (Diener et al., 1985), and happiness scale (Lyubomirsky and Lepper, 1999) along with demographic items, which included age, gender, income, mother's education, and father's education. All the scales were 7-point Likert-type scales, with 1 and 7 representing "strongly disagree" and "strongly disagree" as the anchor points.

\section{Research results}

Structural equation modeling and regression analyses were employed to address the research questions using Mplus 6.0 (Muthén and Muthén, 2010) and SPSS 19 (Brosius, 2011). The Maximum Likelihood (ML) procedure (see Schafer and Graham, 2002) fitted the missing data. The data was subjected to three stages of analyses: (1) confirmatory factor analysis (CFA) to compare goodness-of-fit of alternative measurement models for personality and value materialism items separately, (2) CFA to test goodness-of-fit of alternative measurement models for personality and materialism items combined, and (3) regression analyses to identify discriminant validity of the two hypothesized factors in predicting well-being and their relationship with demographic variables (e.g., age and gender). A similar approach has been successfully used by Bryant and Cvengros (2004) in their study on hope and optimism.

To estimate measurement models, four criteria to assess a model's goodnessof-fit to the data were used, namely the Comparative Fit Index (CFI; Joreskog and Sorbom, 1996), Tucker and Lewis Index of fit (TLI; Tucker and Lewis, 1973), Root Mean Square Error of Approximation (RMSEA; Steiger, 1990) and the Standardized Root Mean Square Residual (SRMR; Hu and Bentler, 1999). Two of these represent measures of relative model fit- the comparative fit index (CFI; Bentler, 1990) and the TLI (TLI; Tucker and Lewis, 1973). CFI and TLI both indicate how much better the given model fits the data relative to a "null" model, namely one that assumes sampling error alone explains the covariation among observed measures (i.e., no common variance among measured variables). Bentler and Bonett (1980) have suggested measurement models have a CFI and TLI of at least .90. RMSEA reflects the size of the 
residuals that result when using the model to predict the data, adjusting for model complexity, with smaller values to indicate a better fit. According to Browne and Cudeck (1993), RMSEA < 0.05 represents "close fit," RMSEA between 0.05 and 0.08 represents "reasonably close fit," and RMSEA > 0.10 represents "an unacceptable model." SRMR is an absolute measure of fit, which refers to the standardized difference between the observed correlation and the predicted correlation. The values for SRMR range from zero to one, with 0.08 or below deemed acceptable (Hooper et al., 2008; Hu and Bentler, 1999).

\section{Determining the structure of personality and value materialism separately}

Personality materialism was subjected to three competing measurement models: (1) one-factor, (2) four-factor, and (3) one-factor parceled. There are different parceling techniques. For the purpose of the present study, random assignment was used (see Hall et al., 1999). The aforementioned models were contrasted to identify the most appropriate measurement model for the personality materialism construct. The goodness-of-fit indices for the models are noted in Table 1 . Likewise, value materialism was subjected to three competing measurement models: (1) one-factor, (2) three-factor, and (3) one-factor parceled. The GFI for the models are noted in Table 2 .

Table 1. Personality materialism: competing measurement models

\begin{tabular}{|l|l|l|l|l|l|l|l|l|}
\hline Model & $\boldsymbol{\chi}^{\mathbf{2}}$ & $\boldsymbol{d} \boldsymbol{f}$ & $\boldsymbol{p}$-value & CFI & TLI & RMSEA & SRMR & $\mathbf{R}^{\mathbf{2}}$ \\
\hline One-factor & 1018.6 & 189 & 0.000 & 0.62 & 0.58 & 0.11 & 0.09 & 20.2 \\
\hline Four-factor & 613.6 & 183 & 0.000 & 0.81 & 0.78 & 0.08 & 0.08 & 47.9 \\
\hline $\begin{array}{l}\text { One-factor } \\
\text { (parceled) }\end{array}$ & 49.2 & 14 & 0.000 & 0.96 & 0.94 & 0.09 & 0.03 & 44.7 \\
\hline
\end{tabular}

Source: Authors' own research.

Table 2. Value materialism: competing measurement models

\begin{tabular}{|l|l|l|l|l|l|l|l|l|}
\hline Model & $\boldsymbol{\chi}^{\mathbf{2}}$ & $\boldsymbol{d} \boldsymbol{f}$ & $\boldsymbol{p}$-value & CFI & TLI & RMSEA & SRMR & $\mathbf{R}^{\mathbf{2}}$ \\
\hline One-factor & 932.6 & 135 & 0.000 & 0.66 & 0.61 & 0.13 & 0.10 & 35.5 \\
\hline $\begin{array}{l}\text { Three- } \\
\text { factor }\end{array}$ & 448.1 & 132 & 0.000 & 0.86 & 0.84 & 0.08 & 0.06 & 55.2 \\
\hline $\begin{array}{l}\text { One-factor } \\
\text { (parceled) }\end{array}$ & 33.3 & 9 & 0.000 & 0.97 & 0.95 & 0.09 & 0.03 & 67.0 \\
\hline
\end{tabular}

Source: Authors' own research.

The statistical analyses at this stage revealed the GFIs for both measures are adequate when a one-factor parceled approach is considered. The scale reliabilities for one-factor (un-parceled) materialism scales were $\alpha=0.51$ and $\alpha=0.85$ for personality and value materialism, respectively. However, the scale reliabilities for the parceled materialism scales were deemed acceptable (i.e., $\alpha>0.70$ ).

\section{Determining the structure of personality and value materialism analyzed together}

For the second stage, four competing measurement models were tested: (1) onefactor model parceled (i.e., all 39 items related to personality materialism and value materialism were analyzed together to reflect one global materialism construct), (2) 
seven-factor model with seven correlated dimensions (i.e., envy, nongenerosity, possessiveness, preservation, acquisition centrality, acquisition happiness, and acquisition success), (3) one second-order factor (i.e., a higher-order model in which a single second-order factor [global materialism] underlies responses to the 39 items) and (4) two second-order factors (i.e., a higher-order model consisting of two correlated second-order factors [personality materialism and value materialism], the first of which underlies the co-variation between the first-order factors of envy, nongenerosity, possessiveness, and preservation, and the second of which underlies the co-variation between the first-order factors of acquisition centrality, happiness, and success. The analyses revealed poor goodness-of-fit for all four measurement models. Relatively, the seven-factor model demonstrated the best goodness-of-fit $\left(\chi^{2}=1778.62\right.$, $d f=681, p=0.000, \mathrm{CFI}=0.78, \mathrm{TLI}=0.76, \mathrm{RMSEA}=0.07, \mathrm{SRMR}=0.08, \mathrm{R}^{2}=54.2$ ). In other words, these results indicate personality and value materialism are two distinct constructs. Furthermore, the shared variance between the two factors was 21 percent, relatively low if the two conceptualizations are considered isomorphic (Ahuvia and Wong, 2002).

\section{Assessing the discriminant validity of personality materialism and value materialism}

Finally, regression analyses were performed with life satisfaction or happiness as the dependent variable and personality or value materialism as the independent variable. Statistical analyses revealed personality materialism was borderline negatively related to life satisfaction $(\beta=-0.15, p=0.01)$ and happiness $(\beta=-0.10, p=0.07)$. On the other hand, value materialism was strongly and negatively related to life satisfaction $(\beta=-0.32, p<0.000)$ and happiness $(\beta=-0.28, p<0.000)$. Furthermore, the relationship between the two materialism conceptualizations and demographic variables (e.g., age, income, gender, father's education, and mother's education) were also explored. Value materialism was negatively related to participant's age $(\beta=-0.16, p<0.1)$, gender $(\beta=-0.19, p<0.01)$, and mother's education $(\beta=-0.14, p<0.1)$. However, value materialism was not related to participant's income and father's education. Whereas, personality materialism was negatively related to gender $(\beta=-0.11, p<0.1)$ and income $(\beta=-0.14, p<0.1)$. Furthermore, personality materialism was not related to age, mother's and father's education. These analyses corroborate the conclusion that personality and value materialism conceptualizations reflect two distinct constructs.

\section{Discussion}

The present study contributes to the materialism literature by explicating the relationship between the central individual personality constructs of personality materialism and value materialism, by highlighting points of their conceptual overlap and divergence, and by demonstrating their discriminant validity in predicting life satisfaction and happiness, and their relationship with demographic variables. Although our study questions the existing dominant individual materialism measurement scales, our analyses suggest if either of the materialism scales were employed in a study (marketing or otherwise), the parceled approach would yield a better fit (for parceling techniques, see Bandalos and Finney, 2001; Hall et al., 1999; Kishton and Widaman, 1994). These results are consistent with previous literature, 
which has questioned the dimensional nature of personality materialism and value materialism. For instance, Eastman et al. (1997) employed Richins and Dawson's (1992) value materialism scale to study materialism in the U.S., China, and Mexico. They found the reliability alphas for value materialism scales ranged from 0.31 to 0.72. Likewise, Evrard and Boff (1998) demonstrated the shortcomings of the personality materialism scale, which suggests both personality materialism and value materialism scales are neither strong nor consistent, reliability wise. For instance, in the present study, the reliabilities of un-parceled materialism scales were $\alpha=0.51$ and $\alpha=0.85$ for personality and value materialism, respectively. These results are consistent with previous findings, which have noted that between the two materialism measurement scales, the personality materialism scale has consistently demonstrated poor reliability when compared to the value materialism scale (e.g., see Larsen et al., 1999). Since materialism has been deemed to be an important construct in consumer behavior and marketing literature (e.g., Ahuvia and Wong, 1995; Richins and Dawson, 1992), which has marketing implications (e.g., market segmentation). In other words, we recommend using the value materialism scale over the personality materialism scale, if the materialism construct is studied. Furthermore, we recommend future research work should address developing a better measurement scale in the case of personality materialism.

Furthermore, our analysis revealed combining personality materialism and value materialism scales to form a single global materialism scale yielded a measurement model with a poor fit. Also, the shared variance between the two constructs was only $21 \%$, indicating the two constructs are separate and are not isomorphic. This is further corroborated by the discriminant validity tests conducted and the relationship with demographic variables explored. Both personality materialism and value materialism predicted life satisfaction and happiness, but with varying strength. Therefore, our study questions the general notion that all materialism results in decrement in individual well-being (e.g., Wright and Larsen, 1993).

Furthermore, demographic variables were related differently for the two materialism measurement scales. For example, the relationship between value materialism and age was statistically significant. Conversely, the aforementioned relationship does not exist in the case of personality materialism.

These findings reinforce the notion using these scales as equivalent contribute to contradictory findings in materialism research. For example, Larsen et al. (1999) determined evidence exists to support materialism as both an enhancer and a destroyer of the environment. Therefore, it is recommended future materialism research studies treat personality materialism and value materialism as separate constructs and not necessarily use the findings of one study to support conclusions about materialism construct investigated in another. The present study suggests the two materialism constructs should be treated as separate constructs.

Finally, in recent years, several scholars have recommended the materialism conceptualization should be changed (e.g., Shrum et al., 2012). First, some conceptualizations are considered priori as negative (e.g., envy and nongenerosity), which limits our understanding of the positive aspects of materialism. Second, different perspectives (i.e., personality trait or value) yield different measurement 
scales that produce different results, as in the present study, providing the impression the effects of materialism are inconsistent, when, in fact, it is the underlying conceptualizations (and the way they are measured) that differ. Furthermore, Shrum et al. (2012) provided a newer definition for materialism that is broader, straightforward, and more concise, namely materialism as "the extent to which individuals attempt to engage in constructions and maintenance of self through the acquisition and use of products...perceived to provide desirable symbolic value." This definition is value free (neither positive nor negative priori) and allows materialism, as a construct, to have negative as well as positive consequences. We echo their suggestion. Our study underscores the importance of reconceptualization of materialism and development of more valid scales that overcome the shortcomings of existing measurement instruments.

\section{References}

Ahuvia, A. (2008), "If money doesn't make us happy, why do we act as if it does?", Journal of Economic Psychology, Vol. 29, pp. 491-507.

Ahuvia, A. and Wong, N. (1995), "Materialism: Origins and implications for personal well-being", European Advances in Consumer Research, Vol. 2, pp. 172-178.

Bandalos, D.L. and Finney, S.J. (2001), "Item parceling issues in structural equation modeling", in G.A. Marcoulides and R.E. Schumacker (Eds.), Advanced structural equation modeling: New developments and techniques, Lawrence Erlbaum Associates, New Jersey.

Belk, R.W. (1985), "Materialism: Trait aspects of living in the material world", Journal of Consumer Research, Vol. 12, pp. 265-280.

Belk, R.W. (1984), "Three scales to measure constructs related to materialism: Reliability, validity, and relationships to happiness", Advances in Consumer Research, Vol. 11, pp. 291-297.

Bentler, P.M. (1990), "Comparative fit indexes in structural models”, Psychological Bulletin, Vol. 107, pp. 238-246.

Bentler, P.M. and Bonnett, D.G. (1980), "Significance tests and goodness of fit in the analysis of covariance structures", Psychological Bulletin, Vol. 88, pp. 588-606.

Brosius, F. (2011), SPSS 19, Hüthig Jehle Rehm: Hamburg.

Browne, M.W. and Cudeck, R. (1993), "Alternative ways of assessing model fit", Sage Focus Editions, Vol. 154, pp. 136-162.

Bryant, F.B. and Cvengros, J.A. (2004), "Distinguishing hope and optimism: Two sides of a coin, or two separate coins?", Journal of Social and Clinical Psychology, Vol. 23, No. 2, pp. 273-302.

Buhrmester, M., Kwang, T. and Gosling, S.D. (2011), “Amazon's Mechanical Turk a new source of inexpensive, yet high-quality, data?", Perspectives on Psychological Science, Vol. 6, No. 1, pp. 3-5.

Chang, L. and Arkin, R.M. (2002), "Materialism as an attempt to cope with uncertainty", Psychology and Marketing, Vol. 19, pp. 389-406.

Christopher, A.N., Lasane, T.P., Troisi, J.D. and Park, L.E. (2007), "Materialism, defensive and assertive self-presentational tactics, and life satisfaction", Journal of social and clinical psychology, Vol. 26, No. 10, pp. 1145-1162. 
Davies, M.A., Manolis, C. and Prince, M. (n.d.), Cross-National Measure Validation of the Material Values Scale: US and UK Samples, available at: www.cerog.org/ lalondeCB/CB/2001_lalonde_seminar/davies.pdf (accessed January 15, 2015).

Dawson, S. and Bamossy, G. (1990), "Isolating the effect of non-economic factors on the development of a consumer culture: A comparison of materialism in the Netherlands and the United States", Advances in Consumer Research, Vol. 17, pp. 182-185.

Diener, E.D., Emmons, R.A., Larsen, R.J. and Griffin, S. (1985), “The satisfaction with life scale", Journal of personality assessment, Vol. 49, No. 1, pp.71-75.

Eastman, J.K., Fredenberger, B., Campbell, D. and Calvert, S. (1997), "The relationship between status consumption and materialism: A cross-cultural comparison of Chinese, Mexican, and American students", Journal of Marketing Theory and Practice, pp. 52-66.

Evrard, Y., and Boff, L.H. (1998), "Materialism and attitudes toward marketing", Advances in Consumer Research, Vol. 25, No. 1, pp. 196-202.

Gay, P. (1984), The Bourgeois Experience: Victoria to Freud, Education of the Senses, Oxford University Press, New York.

Ger, G. and Belk, R. W. (1996), "Cross-cultural differences in materialism", Journal of Economic Psychology, Vol. 17, No. 1, pp. 55-77.

Ghadrian, A-M. (2010), Materialism: Moral and Social Consequences, George Ronald, Oxford.

Hall, R.J., Snell, A.F. and Foust, M.S. (1999), "Item parceling strategies in SEM: Investigating the subtle effects of unmodeled secondary constructs", Organizational Research Methods, Vol. 2, No. 3, pp. 233-256.

Holbrook, M.B. (1987), "Mirror, mirror, on the wall, what's unfair in the reflections on advertising?", The Journal of Marketing, Vol. 51, No. 3, pp. 95-103.

Hooper, D., Coughlan, J. and Mullen, M. (2008), "Structural equation modelling: Guidelines for determining model fit", Business Research Methods, Vol. 6, No. 1, pp. 53-60.

Hu, L.T. and Bentler, P.M. (1999), "Cutoff criteria for fit indexes in covariance structure analysis: Conventional criteria versus new alternatives", Structural Equation Modeling: A Multidisciplinary Journal, Vol. 6, No. 1, pp. 1-55.

Hunt, J.M., Kernan, J.B. and Mitchell, D.J. (1996), "Materialism as social cognition: People, possessions, and perception", Journal of Consumer Psychology, Vol. 5, No. 1 , pp. 65-83.

Jöreskog, K.G. and Sörbom, D. (1996), LISREL 8: User's reference guide, Scientific Software International, Illinois.

Kasser, T. (2002), The High Price of Materialism, MIT Press, Cambridge.

Kasser, T. and Ahuvia, A. (2002), "Materialistic values and well-being in business students", European Journal of Social Psychology, Vol. 32, No. 1, pp. 137-146.

Kasser, T. and Ryan, R.M. (1993), "A dark side of the American dream: Correlates of financial success as a central life aspiration", Journal of Personality and Social Psychology, Vol. 65, No. 2, pp. 410-422.

Kishton, J.M. and Widaman, K.F. (1994), "Unidimensional versus domain representative parceling of questionnaire items: An empirical example", Educational and Psychological Measurement, Vol. 54, No. 3, pp. 757-765. 
Larsen, V., Sirgy, J.M. and Wright, N.D. (1999), "Materialism: The construct, measures, antecedents, and consequences", Academy of Marketing Studies Journal, Vol. 3, No. 2, pp. 78-110.

Lyubomirsky, S. and Lepper, H.S. (1999), “A measure of subjective happiness: Preliminary reliability and construct validation", Social indicators research, Vol. 46, No. 2, pp. 137-155.

Manchiraju, S. (2013), "Materialism in consumer behavior and marketing: A review", Management and Marketing. Challenges for the Knowledge Society, Vol. 8, No. 2, pp. 329-352.

Mannion, C. and Brannick, T. (1995), "Materialism and its measurement", IBAR, Vol. 16.

Murphy, P.E. (1998), "Ethics in advertising: Review, analysis, and suggestions”, Journal of Public Policy and Marketing, Vol. 17, No. 2, pp. 316-319.

Muthén, L. and Muthén, B. (2010), Mplus 6.0, Muthén and Muthén, Los Angeles.

Myers, D.G. (2012), Exploring Social Psychology, McGraw Hill, New York.

Paduska, B. (1992), "Money, marriage, and Maslow's hierarchy of needs", American Behavioral Scientist, Vol. 35, No. 6, pp. 756-770.

Paolacci, G., Chandler, J. and Ipeirotis, P.G. (2010), "Running experiments on Amazon Mechanical Turk", Judgment and Decision Making, Vol. 5, No. 5, pp. 411-419.

Richins, M.L. (1994), "Special possessions and the expression of material values", Journal of Consumer Research, Vol. 21, No. 3, pp. 522-533.

Richins, M.L. and Dawson, S. (1992), "A consumer values orientation for materialism and its measurement: Scale development and validation", Journal of Consumer Research, Vol. 19, No. 6, pp. 303-316.

Rokeach, M. (1973), The Nature of Human Values, Free Press, New York.

Schafer, J.L. and Graham, J.W. (2002), "Missing data: Our view of the state of the art", Psychological Methods, Vol. 7, No. 2, p. 147.

Scitovsky, T. (1976), The joyless economy: An inquiry into human satisfaction and consumer dissatisfaction, Oxford University Press, Oxford.

Shrum, L.J., Wong, N., Arif, F., Chugani, S. K., Gunz, A., Lowrey, T. M., Nairn, A., Pandelaere, M., Ross, S. M., Ruvio, A., Scott, K. and Sundie, J. (2012), "Reconceptualizing materialism as identity goal pursuits: Functions, processes, and consequences", Journal of Business Research, Vol. 66, No. 8, pp 1179-1185.

Sprouse, J. (2011), "A validation of Amazon Mechanical Turk for the collection of acceptability judgment in linguistic theory", Behavioral Research Methods, Vol. 43, No. 1, pp. 155-167.

Steiger, J.H. (1990), "Structural model evaluation and modification: An interval estimation approach", Multivariate Behavioral Research, Vol. 25, No. 2, pp. 173180.

Tucker, L.R., and Lewis, C. (1973), “A reliability coefficient for maximum likelihood factor analysis", Psychometrika, Vol. 38, No. 1, pp. 1-10.

Twitchell, J.B. (1999), “Two cheers for materialism”, The Wilson Quarterly, Vol. 23, No. 2, pp. 16-26.

Van Boven, L. and Gilovich, T. (2003), "To do or to have? That is the question”, Journal of Personality and Social Psychology, Vol. 85, No .6, pp. 1193-1202. 
Watson, J.J. (2003), "The relationship of materialism to spending tendencies, saving, MMCKS and debt". Journal of Economic Psychology, Vol. 24, No. 6, pp. 723-739.

Webster, C. and Beatty, R. C. (1997), "Nationality, materialism, and possession importance", Advances in Consumer Research, Vol. 24, pp. 204-210.

Wright, N.D. and Larsen, V. (1993), "Materialism and life satisfaction: A meta-analysis", Journal of Consumer Satisfaction, Dissatisfaction, and Complaining Behavior, Vol. 6, pp. 158-165. 


\section{MMCKS Appendix I \\ Survey questions}

$102 \quad$ All the scales were 7-point Likert-type scales, with 1 and 7 representing "strongly disagree" and "strongly agree" as the anchor points, unless mentioned otherwise. * denotes reverse-coded items.

\section{Personality Materialism}

1. I enjoy donating things for charity.*

2. I enjoy sharing what I have.*

3. I do not enjoy donating things to the needy.

4. I don't like to lend things, even to good friends.

5. When friends do better than me in competition it usually makes me feel happy for them.*

6. I enjoy having people I like stay in my home.*

7. When friends have things I cannot afford it bothers me.

8. I worry about people taking my possessions.

9. I don't mind giving rides to those who don't have a car.*

10. I get very upset if something is stolen from me, even it has little monetary value.

11. I don't like to have anyone in my home when I'm not there.

12. I don't get particularly upset when I lose things.*

13. I am less likely than most people to lock things up.*

14. I don't seem to get what is coming to me.

15. People who are very wealthy often feel they are too good to talk to average people.

16. If I have to choose between buying something for myself versus for someone I love, I would prefer buying for myself.

17. I am bothered when I see people who buy anything they want.

18. There are certain people I would like to trade places with.

19. I like to collect things.

20. I have a lot of souvenirs.

21. I tend to hang on to things I should probably throw out.

\section{Value Materialism}

1. I admire people who own expensive homes, cars, and clothes.

2. Some of the most important achievements in life include acquiring material possessions.

3. I don't place much emphasis on the amount of material objects people own as a sign of success.*

4. The things I own say a lot about how well I'm doing in life.

5. I like to own things that impress people.

6. I don't pay much attention to the material objects other people own.*

7. I usually buy only the things that I need.*

8. I try to keep my life simple, as far as possessions are concerned.*

9. The things that I own aren't all that important to me**

10. I enjoy spending money on things that aren't practical.

11. Buying things gives me a lot of pleasure.

12. I like a lot of luxury in my life.

13. I put less emphasis on material things than most people I know.* 
14. I have all the things I really need to enjoy life.*

15. My life would be better if I owned certain things I don't have.

MMCKS

16. I wouldn't be any happier if I owned nicer things.*

17. I'd be happier if I could afford to buy more things.

18. It sometimes bothers me quite a bit that I can't afford to buy all the things I'd like.

*Reverse-coded 